\section{Do Pharmacists Have a Role in Recommending Codeine for Pain Management? Australian Perspectives}

\section{THE "PRO" SIDE}

Pharmacists in both community and hospital practice have an established role as medication experts, with the knowledge and skills to assist in management of both minor ailments and chronic conditions. ${ }^{1-3}$ Given that pharmacists are the most accessible health care providers, it seems appropriate that we have a role to play in the treatment of both acute and chronic pain conditions. Recent examples of pharmacist involvement in pain management have been documented. ${ }^{4-6}$

Despite evidence that (1) pharmacists can provide advice to assist patients with pain $^{4-6}$ and (2) there are effective analgesic doses of pain-relieving medicines available over the counter, ${ }^{7}$ there has been ongoing controversy with respect to codeine and a push to up-schedule codeine-containing products to prescription-only status in Australia. ${ }^{8,9}$ This move to up-schedule codeine is in response to the apparent abuse of codeine by some members of the population and the increased potential for dependence and toxic effects in these individuals. In the following paragraphs, we present our thoughts as to why up-scheduling of low-dose codeine makes little sense.

Codeine, an opioid analgesic, occupies the second step of the World Health Organization's analgesic ladder, for use when acetaminophen or a nonsteroidal anti-inflammatory drug (NSAID) may be insufficient as a lone agent for treatment of pain. The analgesic ladder was first introduced in 1986 for cancer pain, and there have been various debates since then regarding its relevance. Nonetheless, a commentary in the Canadian Family Physician outlined that decades after its introduction, this ladder still forms a sensible approach to pain management. ${ }^{10}$ The commentary also contained a pain ladder for noncancer pain, which includes the same step-up from non-opioid-based analgesics to weak opioid analgesics as the pain progresses. ${ }^{10}$ In line with this approach, current Australian therapeutic guidelines recommend doses of 30 to $60 \mathrm{mg}$ of codeine in combination with non-opioid analgesics when the latter are not sufficient on their own for moderate pain. ${ }^{11}$

Small doses of codeine in combination with acetaminophen, ibuprofen, or acetylsalicylic acid, with or without caffeine, are available over the counter in many countries around the world, including Canada and Australia. As writers from Australia, we will shed light on the availability of codeine in Australia, including products with doses of codeine between 8 and $15 \mathrm{mg}$ per tablet, which come with the general recommendation to take 2 tablets every 4 to $6 \mathrm{~h}$. This dosage recommendation means that for the nonprescription product with the largest amount of codeine (which contains acetaminophen $500 \mathrm{mg}$ and codeine $15 \mathrm{mg}$ per tablet), it would be standard for an adult to receive $1000 \mathrm{mg}$ of acetaminophen and $30 \mathrm{mg}$ of codeine in one dose.

A review of the efficacy and safety of over-the-counter codeine-containing combination analgesics was recently commissioned by the Therapeutic Goods Administration, ${ }^{7}$ which is part of the Australian Government Department of Health (equivalent to Health Canada). The review showed that codeine at doses of $30 \mathrm{mg}$ or more was sufficient to provide analgesia for immediate relief of acute pain. ${ }^{7}$ Given that doses up to $30 \mathrm{mg}$ are currently available over the counter in Australia, it seems there are effective analgesic products available that can and should be recommended by pharmacists to assist patients with minor to moderate pain.

We believe that the vast majority of consumers who take over-the-counter codeine-containing analgesics use these products for the treatment of acute pain, use them appropriately for only a short period, do not abuse them, and are at no risk of becoming dependent on codeine.

If these products were rescheduled to be available only by prescription, consumers who use these products would be forced to visit a medical practitioner to obtain a prescription, which would add costs to both the health care system and the consumer. ${ }^{12}$ In addition, it is likely that most consumers would not be able to obtain a timely appointment with a medical practitioner to obtain access to such products to treat their current, acute, short-term pain.

A further concern is that when consumers find out that they can no longer obtain codeine-containing products over the counter, they may turn to other over-the-counter analgesics. This could lead to the inappropriate use of NSAIDS, which in many countries can be purchased in supermarkets and other nonpharmacy outlets without any professional advice. We believe this change in behaviour could lead to the use of doses above the recommended maximum and could increase the risk of adverse drug reactions and drug interactions. For example, patients with conditions such as high blood pressure, heart failure, or renal impairment should use NSAIDS cautiously, if at all. Furthermore, those who are taking various commonly prescribed drugs, includ- 
ing anticoagulants, angiotensin-converting enzyme inhibitors, or diuretics, may experience significant drug interactions if they consume NSAIDs. ${ }^{12}$

It is also likely that if a consumer must go to a medical practitioner to obtain a codeine-containing product, the consumer will most likely be given a prescription for a product with a higher codeine content than the current over-the-counter products. We base this presumption on Australian Medicare data for the period July 2014 to June 2015, which indicate that when health care providers were prescribing analgesics for war veterans, with a choice of prescribing combination analgesics containing 8,15 , or $30 \mathrm{mg}$ codeine, $92.3 \%$ of prescriptions were written for a product containing $30 \mathrm{mg} .{ }^{13}$

Codeine is metabolized to morphine by the cytochrome P450 2D6 isozyme (CYP2D6). Expression of this enzyme is genetically determined, and it has been reported that people who are "ultrarapid metabolizers" are at risk of serious adverse reactions resulting from morphine toxicity. ${ }^{14,15}$ This situation has also been used as an argument for the re-scheduling of codeine to become a prescription-only medication. However, we fail to understand the logic of this rationale. The medical practitioner, like the pharmacist, will not be able to determine a patient's metabolic status without genetic testing, which is clearly impractical.

It has been reported that for the period 2000 to 2013, a total of 1444 codeine-related deaths occurred in Australia, most due to intentional or accidental overdose. ${ }^{16}$ Of these, $83.7 \%$ were due to multiple-drug toxicity, with only $7.3 \%$ of deaths being due to codeine toxicity alone. From these data, it seems that, in Australia at least, serious toxicity and death from the rapid metabolism of codeine to morphine is a rare event. We suspect that trends in Canada may be similar.

The same study ${ }^{16}$ also noted that in about $60 \%$ of cases it could not be determined whether the person obtained the codeine by prescription or over the counter. However, where details about the source were available, the codeine was obtained by prescription in $59.9 \%$ of cases, which indicates that in Australia the majority of codeine products involved in fatalities are prescribed, not obtained over the counter.

In summary, we believe that codeine has a legitimate role in the short-term treatment of acute pain and that it should remain as a product that pharmacists can recommend in combination with products such as acetaminophen and NSAIDs. Because the over-the-counter sale of these products is restricted to pharmacies, where professional advice from the pharmacist is available, we see the arguments for up-scheduling this product to prescription-only status as flawed. Although we do not have exact numbers, it seems reasonable to conclude that codeine-containing products purchased over the counter are used appropriately and legitimately by millions of consumers every year. Although codeine is admittedly misused by some people, we believe that they represent a very small minority of the population.

We believe that collectively punishing millions of legitimate users, by removing codeine as an over-the-counter product, because of the actions of a few is not justified. Just as importantly, we believe that this change will not stop those who abuse codeine from "doctor shopping" to gain access to this drug by prescription.

References

1. Nkansah N, Mostovetsky O, Yu C, Chheng T, Beney J, Bond CM, et al. Effect of outpatient pharmacists' non-dispensing roles on patient outcomes and prescribing patterns. Cochrane Database Syst Rev. 2010;(7):CD000336.

2. Pande S, Hiller JE, Nkansah N, Bero L. The effect of pharmacist-provided non-dispensing services on patient outcomes, health service utilisation and costs in low- and middle-income countries. Cochrane Database Syst Rev. 2013;(2):CD010398.

3. Coelho RB, Costa FA. Impact of pharmaceutical counseling in minor health problems in rural Portugal. Pharm Pract (Granada). 2014;12(4):451.

4. Barbee J Jr, Chessher J, Greenlee M. Pain management: the pharmacist's evolving role. Pharm Times. 2015 Jul 13 [cited 2016 Nov 15]. Available from: www.pharmacytimes.com/publications/health-system-edition/2015/ july2015/pain-management-the-pharmacists-evolving-role

5. Erickson AK. Kocking out pain: hospital pharmacists launch new approach to pain management. Pharm Today. 2015;21(6):5-6. Also available from: https://www.pharmacist.com/knocking-out-pain-hospital-pharmacistslaunch-new-approach-pain-management

6. Philpott L. Pain management and pharmacy. Chatswood (Australia): Australian Pharmaceutical Publishing Company Pty Ltd; 2015 [cited 2016 Nov 15]. Available from: https://ajp.com.au/features/pain-managementand-pharmacy/

7. Shaheed CA, Maher CG, McLachlan A. Investigating the efficacy and safety of over-the-counter codeine containing combination analgesics for pain and codeine based antitussives. Woden (Australia): Government of Australia, Department of Health, Therapeutic Goods Administration; 2016 Mar 21.

8. Haggan M. Four reasons codeine should be S4-but Guild disagrees. Chatswood (Australia): Australian Pharmaceutical Publishing Company Pty Ltd; 2016 [cited 2016 Nov 15]. Available from: https:/ajp.com.au/news/ four-reasons-codeine-s4-guild-disagrees/

9. Yang J, Zlomislic D. Star investigation: Canada's invisible codeine problem. The Star [Toronto, ON]: 2015 Jan 17 [cited 2016 Nov 15]. Available from: https://www.thestar.com/news/canada/2015/01/17/star-investigationcanadas-invisible-codeine-problem.html

10. Vargas-Schaffer G. Is the WHO analgesic ladder still valid? Twenty-four years of experience. Can Fam Physician. 2010;56(6):514-7.

11. Acute pain: a general approach. In: Therapeutic guidelines: analgesic version 6, 2012 [part of eTG Complete]. Melbourne (Australia): Therapeutic Guidelines Limited; [revised 2012 Nov; cited 2016 Jul]. Available from: http://new.tg.com.au/index.php?sectionid=18. Subscription required to access content.

12. Carroll P, Moles R, Matthews S, Nankivell S, Logan N. Why upscheduling codeine combination products is a really bad idea. Chatswood (Australia): Australian Pharmaceutical Publishing Company Pty Ltd; 2015 [cited 2016 Nov 15]. https://ajp.com.au/columns/opinion/why-upscheduling-codeinecombination-products-is-a-really-bad-idea/

13. Medicare Australia statistics: pharmaceutical benefits schedule item reports. Canberra (Australia): Australian Government, Department of Human Services; [cited 2016 Nov 15]. Available from: http://medicarestatistics. humanservices.gov.au/statistics/pbs_item.jsp

14. Racoosin J, Robertson D, Pacanowski M, Neilson D. New evidence about an old drug-risk with codeine after adenotonsillectomy. $N$ Engl J Med. 2013;368:2155-7.

15. Gasche Y, Daali Y, Fathi M, Chiappe A, Cottini S, Dayer P, et al. Codeine intoxication associated with ultrarapid CYP2D6 metabolism. NEnglJMed. 2004;351:2827-31.

16. Roxburgh A, Hall WD, Burns L, Pilgrim J, Saar E, Nielsen S, et al. Trends and characteristics of accidental and intentional codeine overdose deaths in Australia. Med J Aust. 2015;203(7):299.

Peter R Carroll, BPharm, MSc, PhD, FPS, FACP

Discipline of Pharmacology, Sydney Medical School

Rebekah Moles, BPharm, DipHospPharm, PhD,

GradCertEdStud(Higher Ed)

Faculty of Pharmacy

The University of Sydney

Sydney, New South Wales, Australia

Rebekah Moles is also an Associate Editor with the Canadian Journal of Hospital Pharmacy.

Competing interests: None declared. 


\section{THE "CON" SIDE}

Codeine, a weak agonist of the mu opioid receptor, is a pharmacogenomically complex, only somewhat efficacious analgesic, generally considered to be a pro-drug of the strong opioid morphine. In reality, the situation is much more complicated, and codeine is often prescribed by pharmacists and physicians in combination with other medicines that, when the formulations are abused, cause immense harm. ${ }^{1,2}$

Codeine has come under international scrutiny and criticism as being too addictive, thus warranting increased restrictions on supply. Currently in Australia, no physician's prescription is required for amounts of up to $15 \mathrm{mg}$ codeine per dose unit, which can be supplied upon clinical judgment of the pharmacist; however, after a recent review by the national drug regulatory body, the Therapeutic Goods Administration, Australian pharmacists face losing the right to give codeine independently. So-called "up-scheduling" would take codeine from Australian Schedule 3 (Pharmacist Only Medicine, a category already subject to effective restriction, at least in theory) to Schedule 4 (Prescription Only Medicine).

As an opioid, codeine carries significant addiction risks, even at therapeutic doses, and is often prescribed by community pharmacists under levels of pressure that are simply not conducive to appropriate pharmaceutical management. The modern "discount" or "warehouse-style" pharmacy practice model often cannot provide the support structures that clinicians need for adequate care, and this model is only increasing in prevalence internationally as profit margins shrink. This is not to say that pharmacists are incapable of such care — quite the opposite ${ }^{3}$ - but when impossible workloads are combined with the public's current view of the role of the pharmacists, we simply cannot expect high-quality care from a large portion of the community pharmacy sector. Furthermore, real-time monitoring systems to record codeine supply against a patient's records, such as the recently implemented Australian MedsASSIST, are a good idea in theory, but such systems are unrealistic if they are not made compulsory. In addition, an issue unique to community pharmacy is the fact that substances that are legislatively and clinically restricted to being supplied by pharmacists with extensive training in pharmacotherapeutics — and rightly so-are often provided to the public by pharmacy support staff. Despite the usefulness of pharmacy assistants, they are neither qualified nor sufficiently educated to prescribe codeine or other restricted drugs. Although information on pharmacy assistants' role in codeine supply specifically is lacking, other data about poor interventional care by assistants has been documented for similarly regulated drugs. ${ }^{4}$

However, reasons related to pharmacists' workload and the potential for addiction are, on their own, weak arguments for taking codeine away from pharmacists. Below are some further arguments as to why codeine should not be up-scheduled, but rather should be done away with altogether.

It is known that the minimum dose of codeine required for most cytochrome P450 2D6 (CYP2D6) phenotypes is about
$30 \mathrm{mg}$ per dose. ${ }^{5}$ This quantity is approached by only the highest-dose pharmacist-prescribed formulations (in Australia, 2 tablets of acetaminophen $500 \mathrm{mg}$ with codeine $15 \mathrm{mg}$ or ibuprofen $200 \mathrm{mg}$ with codeine $12.8 \mathrm{mg}$; in Canada, 3 tablets of the combination acetaminophen $300 \mathrm{mg}$, caffeine $15 \mathrm{mg}$, and codeine $8 \mathrm{mg}$ ). Although these products at their highest doses are supported by evidence of efficacy, it is known that a large number of codeine-containing products on the market do not come anywhere near a 30-mg dose of codeine, yet they still induce the adverse outcomes associated with codeine, such as constipation and sedation. ${ }^{5}$

It is also known that a substantial proportion of injury associated with over-the-counter codeine preparations comes from the other drugs that are present in coformulations, such as acetaminophen or ibuprofen. In these combination products, the ratio of codeine to other drugs is so low that abusers must take huge doses to get an opioid effect. As a result, the other substances are consumed at supratherapeutic doses, leading to adverse effects such as gastrointestinal hemorrhage and renal tubular acidosis (ibuprofen-based products ${ }^{6-10}$ ) or hepatotoxicity (acetaminophenbased products $\left.{ }^{11}\right)$.

Opioid dependence is a growing and very serious issue. In 2013, a colossal 12.376 million milligrams of codeine was consumed by Australians, ${ }^{2,12,13}$ which equates to about $554 \mathrm{mg}$ per capita. ${ }^{12}$ It should be noted that the majority $(60 \%)$ of this codeine mass was obtained through physicians prescriptions, ${ }^{12}$ but an attempt should be made to limit the use of codeine in all primary care settings.

The most convincing argument for removing codeine from pharmacy shelves relates to the unpredictable effects resulting from its complex and poorly characterized metabolism. A large proportion of codeine's analgesic effect is thought to come from its CYP2D6 metabolism into morphine. Not only does the CYP2D6 enzyme have wildly variable expression across populations, but it is induced and inhibited by many common medicines and environmental factors. ${ }^{14,15}$ This means that even in the "average" patient, dose response is unknown before administration, which makes standardization impossible and outcomes uncertain.

The primary reason for making codeine available over-thecounter was the belief that the CYP2D6 pathway becomes saturated at supratherapeutic doses. However, this hypothetical ceiling dose has never been determined. Regardless, a 1998 study ${ }^{16}$ showed side effect profiles that were indistinguishable between patients with extensive CYP2D6 metabolism (who produced relatively large amounts of morphine) and those who lacked the enzyme (and thus could not produce relevant quantities of morphine). This study presented compelling evidence to suggest that the adverse outcomes are morphine-independent, which is to say, they present without the involvement of the CYP2D6 enzyme. Therefore, the ceiling dose theory is likely moot.

Morphine is a cleaner drug, with simpler pharmacology and simpler pharmacokinetics, and it possesses fewer metabolites, with 
fewer enzymatic pathways. This is the true nail in the coffin for codeine: it is wholly inferior to morphine in every way. Furthermore, morphine is no riskier than codeine. Recent research suggests that low-dose morphine has no greater addiction potential than does a weak opioid, and that codeine possesses dose-dependent adverse outcomes equal to those of morphine. ${ }^{17}$ Low-dose morphine would be a vastly superior preparation for pain management than codeine, and those whose pain cannot be controlled with morphine-based formulations would be beyond the help of a weak opioid such as codeine anyway.

Not having opioids available over the counter is also not a solution. Although there is some evidence ${ }^{18}$ that nonsteroidal anti-inflammatory drugs (NSAIDs) or NSAID/acetaminophen combinations are superior to lower doses of codeine for some indications, this evidence is unconvincing in practice, because of the large proportions of the population in whom NSAID therapy is ill-advised (such as those with cardiovascular disease, coagulopathy, or renal impairment). There is also evidence that codeine/acetaminophen combinations are superior to singleingredient acetaminophen alone, which suggests that acetaminophen on its own is often insufficient and that an opioid such as morphine, accessible to the public under the supervision of a pharmacist, without a physician's prescription, would be advantageous. ${ }^{19}$ The availability of effective pain relief provided by a trained practitioner also reduces the risk of patients selfmedicating with NSAIDs (which are available from supermarkets without pharmaceutical advice) to supplement an ineffective acetaminophen dose in cases where such therapy would be dangerous.

We could even use the transition from codeine to morphine as an opportunity to rewrite and reinforce existing, alreadyrestrictive legislative controls on codeine for the new preparations, and to reset the public's perception of the roles of both opioids and pharmacists in the primary care management of pain.

Therefore, ideally, pharmacists should no longer give codeine to patients for acute pain, but neither should physicians. Instead, we should use a well-known, predictable, and reliable drug like morphine, in low-dose combinations with acetaminophen. Morphine is cheap, it's familiar, it's better characterized, and it's readily available. Replacing codeine with morphine simply cuts out the metabolism black box, yielding an end result with greater predictability, less inter-patient variability, and more control for the clinician. This could be a promising future option for the management of pain in primary care.

\section{References}

1. McAvoy BR, Dobbin MD, Tobin CL. Over-the-counter codeine analgesic misuse and harm: characteristics of cases in Australia and New Zealand. NZMed J. 2011;124(1346):29-33.
2. Robinson GM, Robinson S, McCarthy P, Cameron C. Misuse of over-thecounter codeine-containing analgesics: dependence and other adverse effects. NZMed J. 2010;123(1317):59-64.

3. Erickson AK. Knocking out pain: hospital pharmacists launch new approach to pain management. Pharm Today. 2015;21(6):5-6. Also available from: https://www.pharmacist.com/knocking-out-pain-hospital-pharmacistslaunch-new-approach-pain-management

4. Schneider CR, Everett AW, Geelhoed E, Kendall PA, Murray K, Garnett $\mathrm{P}$, et al. Provision of primary care to patients with chronic cough in the community pharmacy setting. Ann Pharmacother. 2011;45(3):402-8.

5. Shaheed CA, Maher CG, McLachlan A. Review of the efficacy and safety of over-the-counter codeine combination medicines. Woden (Australia): Government of Australia, Department of Health, Therapeutic Goods Administration; 2016 [cited 2016 Aug]. Available from: https:// www.tga.gov.au/alert/review-efficacy-and-safety-over-counter-codeinecombination-medicines

6. Frei MY, Nielsen S, Dobbin MDH, Tobin CL. Serious morbidity associated with misuse of over-the-counter codeine-ibuprofen analgesics: a series of 27 cases. Med J Aust. 2010;193(5):294-6.

7. Dyer BT, Martin JL, Mitchell JL, Sauven NC, Gazzard BG. Hypokalaemia in ibuprofen and codeine phosphate abuse. Int J Clin Pract. 2004;58(11): 1061-2.

8. Dutch MJ. Nurofen Plus misuse: an emerging cause of perforated gastric ulcer. Med J Aust. 2008;188(1):56-7.

9. McAvoy BR, Tobin CL. Fatal misuse of codeine-ibuprofen analgesics in Victoria, Australia [letter]. Med J Aust. 2014;200(3):150-1.

10. Pilgrim JL, Drummer OH. Fatal misuse of codeine-ibuprofen analgesics in Victoria, Australia [reply]. Med J Aust. 2014;200(3):151.

11. Larson AM, Polson J, Fontana RJ, Davern TJ, Lalani E, Hynan LS, et al. Acetaminophen-induced acute liver failure: results of a United States multicenter, prospective study. Hepatology. 2005;42(6):1364-72.

12. Gisev N, Nielsen S, Cama E, Larance B, Bruno R, Degenhardt L. An ecological study of the extent and factors associated with the use of prescription and over-the-counter codeine in Australia. Eur J Clin Pharmacol. 2016;72(4):469-94

13. Dobbin M, Tobin C. Over the counter (OTC) ibuprofen/codeine analgesics: misuse and harm [brief]. National Drugs and Poisons Schedule Committee (Australia); 2008 May 22.

14. Williams DG, Patel A, Howard RF. Pharmacogenetics of codeine metabolism in an urban population of children and its implications for analgesic reliability. Br J Anaesth. 2002;89(6):839-45.

15. McMillan D, Tyndale R. Nicotine increases codeine analgesia through the induction of brain CYP2D and central activation of codeine to morphine. Neuropsychopharmacology. 2015;40(7):1804-12.

16. Eckhardt K, Li S, Ammon S, Schänzle G, Mikus G, Eichelbaum M. Same incidence of adverse drug events after codeine administration irrespective of the genetically determined differences in morphine formation Pain. 1998;76(1-2):27-33.

17. "Weak" opioid analgesics. Codeine, dihydrocodeine and tramadol: no less risky than morphine. Prescrire Int. 2016;25(168):45-50.

18. Drendel AL, Gorelick MH, Weisman SJ, Lyon R, Brousseau DC, Kim MK A randomized clinical trial of ibuprofen versus acetaminophen with codeine for acute pediatric arm fracture pain. Ann Emerg Med. 2009;54(4):553-60.

19. de Craen AJ, Di Giulio G, Lampe-Schoenmaeckers JE, Kessels AG, Kleijnen J. Analgesic efficacy and safety of paracetamol-codeine combinations versus paracetamol alone: a systematic review. BMJ. 1996;313(7053):321-5.

Joel Hillman, PBPharm, MSHPA, RPh

Faculty of Pharmacy

The University of Sydney

Sydney, New South Wales, Australia

Joel Hillman is a doctoral student and practises in the Prince of Wales Private Hospital, Sydney, Australia.

Competing interests: None declared 